\title{
The Effectiveness of Task-Based Instruction on the Reading Comprehension Ability of EFL Students at the University of Tabuk
}

\author{
Abdussalam M. Aliia Kamariah Yunus Salah M. Ali \\ Mohammad M. Alia Hafez H. Alghafow \\ The Faculty of Languages and Communication, Universiti Sultan Zainal Abidin
}

\begin{abstract}
The present study examined the effectiveness of task-based instruction (TBI) in improving the reading comprehension ability of EFL students at the University of Tabuk. In order to conduct this study, 80 EFL students at the University of Tabuk, who have taken Placement Test (TUPT) as a pre-test, were chosen for the study. The participants of the study were selected randomly. The researcher used reading comprehension tasks and Placebo Task (Pre- / Post-test) as the research instruments of the study. The findings of this study revealed that students in the experimental group outperformed students in the control group. Thus, task-based instruction was considered to be effective in increasing the reading comprehension ability.
\end{abstract}

Keywords: Tasks, Language learning development, Reading comprehension, EFL students

DOI: $10.7176 / \mathrm{JLLL} / 54-02$

Publication date:March $31^{\text {st }} 2019$

\section{Introduction}

Reading comprehension can be considered as important language ability and a central means for learning new information in a second or foreign language context. It is one of the most important skills which are essential for students' success and it may enhance the process of language acquisition as well as assisting learners to learn different materials for many different purposes. The ability to read means extracting information from a text and connecting it with the information students already have. Furthermore, Reading can be referred to as a meaningconstruction process and which involves interaction between texts and readers, perceptual and comprehension processes, careful attention, memory, and understanding words as well as sentences. Moreover, reading involves a complex integration of prior knowledge, language proficiency, and metacognitive strategies (Rosenshine, 2017). Students can improve reading comprehension of texts assignments and direction on exams by approaching appropriate reading passages. To Blachowicz \&. Ogle (2017) appropriate materials can be helpful in improving the reading ability when readers try to understand the discourse structure and organization of the reading passage. If students are familiar with the different types of reading materials, then reading comprehension can be improved. Moreover, reading comprehension will be increased if these materials are related to understanding the obvious facts, implications, and suppositions of the text (Ness, 2016).

During the past few years, the views on how to teach reading comprehension have been rapidly changed. Task-based instruction approach is different from the traditional approaches. In fact, in the task-based approach lessons are in terms of required language to perform a set of tasks rather than based on some aspects of language such as structure and vocabulary. In other words, task-based instruction is widely used for the learning of a second or foreign language. Branden (2016) divided the task-based Instruction method into three sections: the pre-task, the task-cycle, and the language focus. Prabhu was the first one developed task-based learning. According to Prabhu (1987), students are able to learn more effectively when their minds are concentrated on the task. Other researchers like Ellis (2018) explored how task-based instruction was useful among the primary school students. The findings of this study showed that the performance of the experimental group improved after the experiment.

A large of number researchers (e.g. Tsai, 2015; Markee, 2015; Chen, 2016; Lee, 2016) emphasized the role of authentic materials in the form of tasks in improving the reading comprehension ability. To Chalak (2015) "task" is considered as an activity in the classroom which involves language use to achieve a communicative purpose. For Ellis (2018), a task is an activity which calls for meaning focused language use. Zheng \& Borg (2014) refer to the fact that pedagogical tasks have important roles in second language acquisition and as useful tools for language teachers. Thomas (2015) believed that task is considered as a means of eliciting samples from language learners and as Lambert \& Kormos (2014) stated it can be a device that organizes the content and methodology of language teaching.

In language classrooms, tasks can be used for practicing a particular structure, function, or sub-skill. According to Ellis (2018) tasks provide a purpose for activity which is beyond the practice of language for its own sake. Performing a task needs active participation and cooperation of students, and they should exchange information on a problem they have faced through tasks. 
Reading tasks are to some extent different from reading exercises. Rozati (2014) refers to the distinction among task, exercise, and activity. To Nunan (2015), tasks are communicative acts that usually do not include a restrictive focus on a single grammatical structure. An exercise usually focuses on a single language element and it contains a linguistic outcome. An activity consists of a restrictive concentration on one or more language items. However, learners, as language users, are required to participate in an activity through tasks and they focus on conveying meaning (Ganta, 2015).

Therefore, the same communicative processes present in real life activities should be employed by learners in classrooms to prepare them for their future jobs. Exercises may contain some purely language related results. In contrast, tasks may include non-linguistic results and language results. To Pellerin (2014), helpful comprehension tasks will be challenging, they keep the students' interest, maintain the students' efforts at task completion, and help them to concentrate on meaning.

The review of previous literature shows that improving the reading comprehension ability can be considered as a critical procedure and will help to acquire a second language. As in the rest of other EFL contexts, reading comprehension is undeniable in Arab countries in general and Saudi Arabia in specific. Hence, this issue has attracted the attention of many researchers and linguists. Therefore, it seems that the majority of Saudi students may face some problems to improve their reading abilities. Even though there have been many attempts to deal with this weakness among EFL students at the University of Tabuk, they did not seem to be applicable.

Finally, students require a reasonable solution for their reading deficiencies that has remained vague until now. In addition, the present study came as a response to the need for more research to improve students' reading comprehension ability. In this regard, the main purpose of this study is to employ a task-based method of teaching reading comprehension and also to investigate its impact on the development of the reading ability in comparison with the traditional and conventional methods of teaching reading comprehension. To come to these ends, the following research question is proposed.

1. What is the effectiveness of task-based instruction on the reading comprehension ability of EFL students at the University of Tabuk?

\section{Methodology}

\subsection{Participants}

The participants of the present study were 80 EFL students at the University of Tabuk, Saudi Arabia, whose major was English Language and Translation. The sampling method for selecting participants was a random selection. The 80 students were randomly assigned to two groups, 40 participants in the experimental group and 40 participants in the control group.

\subsection{Instruments}

The instruments of this study included Tabuk University Placement Test (TUPT) and a final test which were conducted to collect the required data. The TUPT test was given to both groups as a pre-test to catch the initial differences among student participants and as a post-test to explore the effects of treatment and how the students have improved. The final test was an end-of-the-course test in terms of the students' course book which was Select Readings by (Soars, 2014).

\section{Design and Procedure}

Both experimental and control groups received instruction for 15 sessions which were part of their university study. In this study, the regular university course and additional tasks were parts of the procedures. In each session, both the control and experimental groups finished a complete unit of their course book. Then, students in the experimental group were received additional material. However, the students in the control group just received placebo in which they were asked to do some exercises in the textbook.

This additional material contained some reading comprehension tasks. The researcher asked students to work in groups on a number of tasks and discuss the answers to these tasks with their classmates. The tasks were taken from a number of sources (Doff \& Jones, 2010; Hartley \& Viney, 2000; Richards, 2012; Lee \& Gundersen, 2014). These tasks were organized from less challenging to most challenging to keep their arrangement within the acceptable sequence of difficulty (Ellis, 2012). Starting with less challenging tasks at the primary sessions familiarized the students with the characteristics of the tasks, and made them ready for doing challenging tasks. Students in experimental and control groups received a pre-test, a post-test, and a final test. The pre-test was Tabuk University Placement Test which was given to whole students before placing the students in experimental and control groups. Then the students' scores on TUPT were analyzed to ensure the homogeneity among the participants of this study before receiving the treatment. The TUPT was conducted again at the end of the treatment to both groups to compare the reading comprehension ability of both experimental and control groups. The final test that was an achievement test presented by the teacher-researcher to test students' achievement in 
the course. The aim of the final test was to measure the two groups' end-of-the-course language proficiency development.

\section{Results}

In order to compute the reliability of the instruments used in this study, the researcher employed the KuderRichardson's reliability coefficient (KR-21). The results of Kuder-Richardson's reliability coefficient revealed that all pre, post, and the final tests were $.86, .88$, and .82 respectively, which were all within the range of acceptable reliability. In order to be sure whether students in both experimental and control groups are homogeneous at the beginning of the study in terms of their reading ability, a t-test was conducted on their test scores on the pre-test (TUPT). As indicated in Table 1, the mean differences of the experimental and control group was 1.36 .

Moreover, the results of the Levene's test revealed that two groups were homogeneous in terms of their variances. In addition, the same performance of the students in these two groups showed that they were equal in terms of reading comprehension ability at the beginning of the study before receiving the treatment.

Table.1: Independent T-test for Pre-test

Levene's Test for Equality of Variances

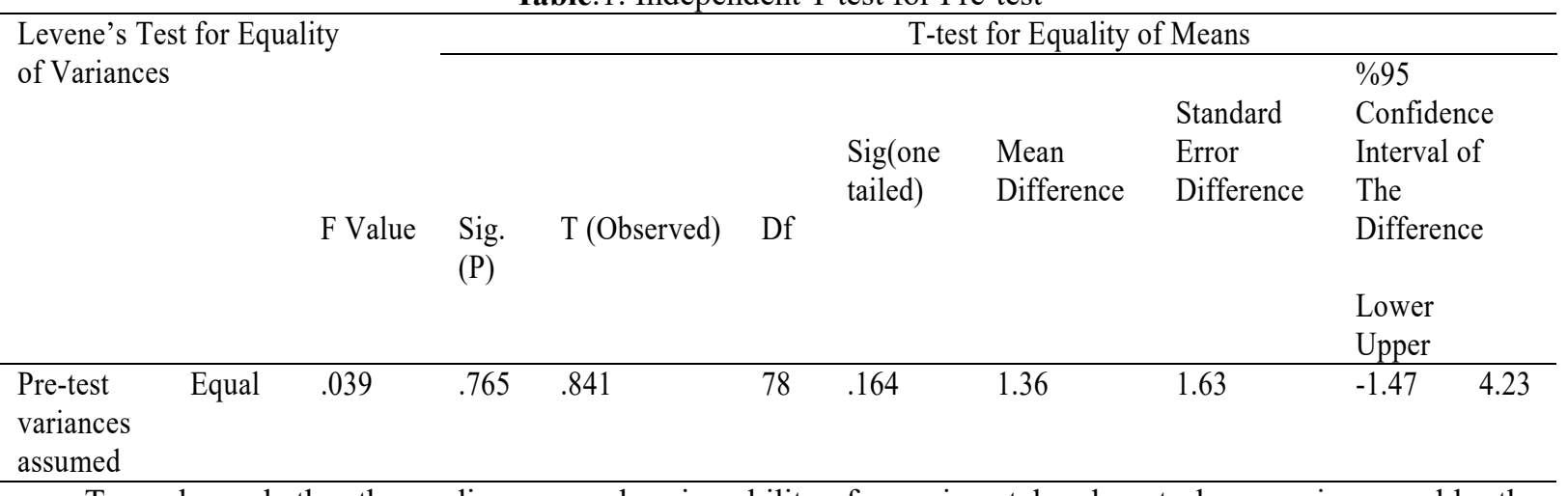

To explore whether the reading comprehension ability of experimental and control groups improved by the end of the experiment, a t-test was run to compare the mean scores of these two groups in the post-test.

As illustrated in Table 2, the T-observed value was $(\mathrm{t}=13.456)$. The $\mathrm{t}$-value at 78 degree of freedom is $(\mathrm{p}$ $=.000$ one tailed) was higher than the critical T-value of 1.25. The outcome indicated that there was a statistically significant difference between the mean scores of the experimental group as well as control group at the end of the study. This means that students in the experimental group performed better than students in the control group in the post-test.

Table.2: Independent T-test for Post-test

Levene's Test for Equality of Variances
T-test for Equality of Means

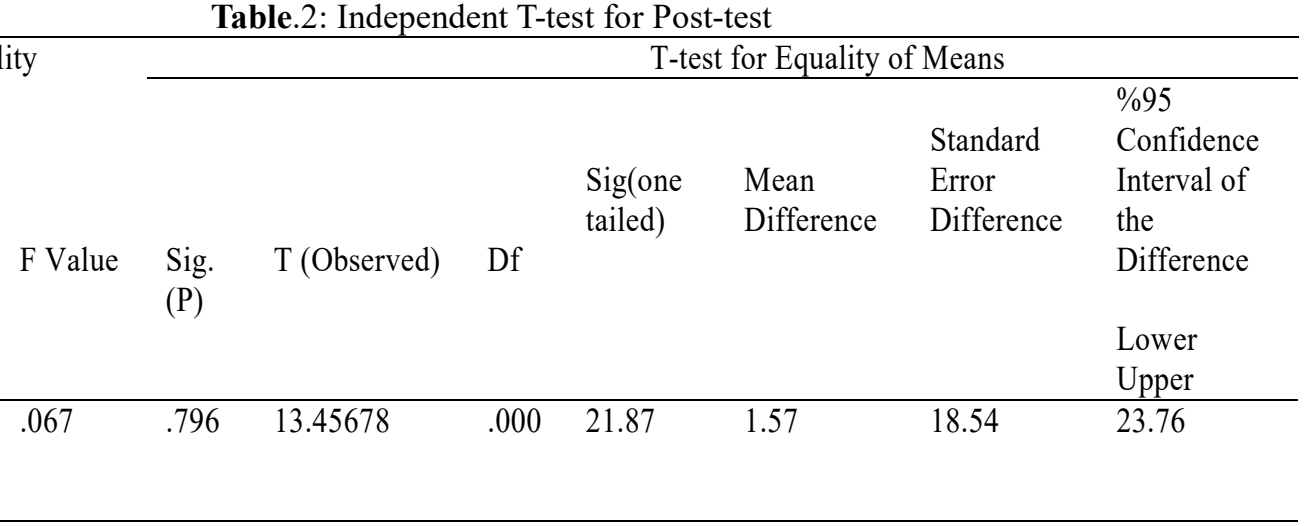

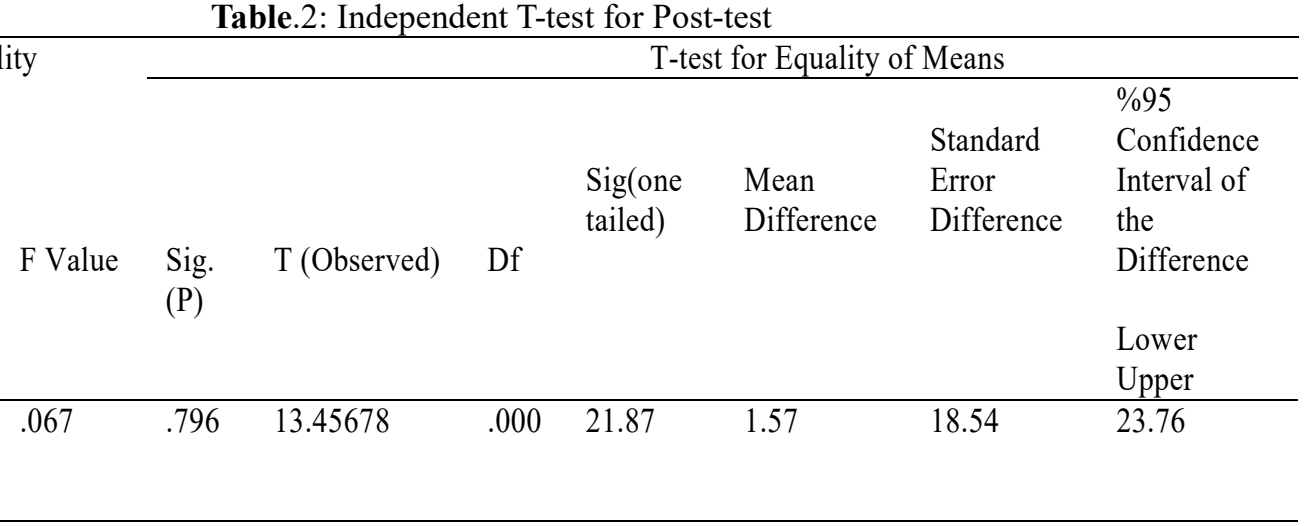

\begin{tabular}{llllllllll}
$\begin{array}{l}\text { Pre-test } \\
\text { variances }\end{array}$ & Equal & .067 & .796 & 13.45678 & .000 & 21.87 & 1.57 & 18.54 & 23.76 \\
assumed & & & & & & & & & \\
\hline
\end{tabular}

\section{Conclusion and Discussion}

The present study investigated the effectiveness of implementing task-based instruction in improving reading comprehension ability among the Tabuk University EFL students. This study also showed that classroom tasks are very effective in improving students' reading ability, because they employ situational and interactional authenticity to a large extent, engage learners in using language pragmatically rather than displaying language, and require learners to employ cognitive processes such as selecting, classifying, ordering, reasoning, or evaluating information in order to carry out the task" (Hamdan, 2014).

To answer research question, and investigate the effectiveness of task-based instruction on improving of the reading comprehension ability among the Saudi students, the researcher selected the experimental research design. Moreover, the overall performance of the students in both experimental and control groups was investigated. Their performance was also compared. The results of t-test which compared the performance of the 
students in both experimental and control groups in the post-test indicated a significant difference between the mean scores of these two groups. Students in the experimental group outperformed students in the control group. These results indicate that task-based instruction can significantly improve the reading comprehension ability among the EFL students at the University of Tabuk.

The results of this research were in line with the findings of other studies which considered tasks as valuable activities to be employed in the language classrooms. According to Willis (2013), tasks have some influential effects on the nature of performance. Moreover, they are tasks which lead to greater fluency and complexity, less dependable, and greater accuracy (Thomas \& Reinders 2010).

The findings of this research were sufficiently convincing to be applied successfully on other EFL contexts in Saudi Arabia. It can also give some insights to teachers and course designers to use tasks in teaching syllabi. Therefore, it is recommended that EFL teachers incorporate tasks in their classrooms to improve reading skills among Saudi EFL students.

\section{References}

Blachowicz, C., \& Ogle, D. (2017). Reading comprehension: Strategies for independent learners. Guilford Publications.

Chalak, A. (2015). The effect of task-based instruction on reading comprehension of Iranian EFL learners. Applied Research on English Language, 4(1), 19-30.

Chen, J. C. (2016). The crossroads of English language learners, task-based instruction, and 3D multi-user virtual learning in Second Life. Computers \& Education, 102, 152-171.

Doff, A., \& Jones, C. (2010). Language in use: beginner. Classroom book. Cambridge: Cambridge University Press.

Ellis, R. (2018). Taking the critics to task: The case for task-based teaching. New Perspectives on the Development of Communicative and Related Competence in Foreign Language Education, 28, 23.

Ganta, T. G. (2015). The strengths and weaknesses of Task-based learning (TBL) approach. Scholarly research journal for interdisciplinary studies, 3(16), 2760-2771.

Hamdan, M. H. (2014). KWL-Plus Effectiveness on Improving Reading Comprehension of Tenth Graders of Jordanian Male Students. Theory \& Practice in Language Studies, 4(11).

Hartley, B., \&Viney, P. (2000). American streamline: Connections. Oxford: Oxford University Press.

Lambert, C., \& Kormos, J. (2014). Complexity, Accuracy, and Fluency in Task-based L2 Research: Toward More Developmentally Based Measures of Second Language Acquisition. Applied Linguistics, 35(5).

Lee, L. (2016). Autonomous learning through task-based instruction in fully online language courses. Language Learning \& Technology.

Lee, L., \& Gundersen, E. (2014) Select reading: pre-intermediate. Oxford: Oxford University Press.

Markee, N. (2015). Giving and following pedagogical instructions in task-based instruction: An ethnomethodological perspective. In International perspectives on ELT classroom interaction (pp. 110-128). Palgrave Macmillan, London.

Ness, M. K. (2016). Reading comprehension strategies in secondary content area classrooms: Teacher use of and attitudes towards reading comprehension instruction. Reading Horizons, 49(2), 5.

Nunan, D. (2015). Teaching English to speakers of other languages: An introduction. Routledge.

Pellerin, M. (2014). Language Tasks Using Touch Screen and Mobile Technologies: Reconceptualizing TaskBased CALL for Young Language Learners. Canadian Journal of learning and Technology, 40(1), n1.

Richards, J. C. (2012). New interchange: English for international communication: book two. Cambridge: Cambridge University Press.

Rosenshine, B. V. (2017). Skill hierarchies in reading comprehension. In Theoretical issues in reading comprehension (pp. 535-554). Routledge.

Rozati, S. M. (2014). Language teaching and task based approach. Theory \& Practice in Language Studies, 4(6).

Soars, L. \& Soars, J. (2014). New Headway Plus. Oxford, London.

Thomas, M. (2015). Contemporary task-based language teaching in Asia. Bloomsbury Publishing.

Thomas, M., \& Reinders, H. (Eds.). (2010). Task-based language learning and teaching with technology. A\&C Black.

Tsai, S. C. (2015). Implementing courseware as the primary mode of task-based ESP instruction: A case study of EFL students. Computer Assisted Language Learning, 28(2), 171-186.

Van den Branden, K. (2016). Task-based language teaching. The Routledge handbook of English language teaching, 238-251.

Willis, J., \& Willis, D. (2013). Doing Task-Based Teaching-Oxford Handbooks for Language Teachers. Oxford University Press.

Zheng, X., \& Borg, S. (2014). Task-based learning and teaching in China: Secondary school teachers' beliefs and practices. Language Teaching Research, 18(2), 205-221. 